\title{
Els molts reptes d'un ensenyament de les Ciències basat en la indagació: ens aportaran múltiples beneficis en l'aprenentatge?
}

\author{
Laurence Viennot \\ Université Paris-Diderot
}

(Traducció de la ponència presentada al Congrès de la GIREP -Groupe International de Recherche sur l'Enseignement de la Physique- a Reims, el 2010)

Atès el que sabem per la recerca sobre l'ensenyament de la física, com podem maximitzar els beneficis en l'aprenentatge a partir d'un Ensenyament de les Ciències basat en la indagació (IBSE ${ }^{1}$ per les sigles en anglès)? Els beneficis s'entenen en termes de conceptes assolits tot mantenint la motivació entre els estudiants.

Per tal de documentar aquesta qüestió es presenten i discuteixen una sèrie d'exemples que es troben en el marc d'experiments simples utilitzats normalment com a punt de partida en activitats d'IBSE sobre física. Els exemples escollits il/lustren alguns dels obstacles que es poden trobar a l'hora de fer un fructífer ensenyament basat en la indagació $i$, al mateix temps il/lustren algunes alternatives a les pràctiques rituals d'ensenyament. Es mostra que aquests rituals donen Iloc a una tendència dels mestres a fer raonar els estudiants en sintonia entre ells de manera que s'ajudin els uns als altres, fent servir el que en el present estudi s'anomena "explicació en eco". Per tal de superar els corresponents inconvenients es propugna afavorir vincles conceptuals en els estudiants. Aquesta proposta està basada en la primera avaluació d'un projecte extens i recent sobre l'IBSE $i$ està associada a diverses de les conclusions obtingudes. Especialment, està basada en les conclusions relacionades en com gestionar la necessàries transicions entre un ensenyament basat en l'IBSE $i$ unes estratègies organitzades de forma més conceptual.

Paraules clau: educació en ciències basada en la recerca, IBSE, explicació eco, pràctiques rituals d'ensenyament, vincles conceptuals, pressió, anàlisi sistèmica, raonament causal lineal

\section{INTRODUCCIÓ}

S'ha afirmat sovint que l'ús del que ara s'anomena Ensenyament de les Ciències basat en la indagació (IBSE en endavant) pot millorar l'interès dels nens i dels estudiants en general envers la ciència. L'IBSE sustenta algunes de les estratègies que tenen com a objectiu promoure la física en contextos formals o informals i influir en la orientació professional dels joves. Aquesta pràctica pot contemplar-se com una bona forma de mostrar als nens i als estudiants de més edat com funciona la ciència tot posant-los en un context on poden estar actius.
Aquesta opinió és àmpliament compartida entre investigadors en didàctica de la física i també per autoritats acadèmiques Per altra banda, informes de diverses institucions i grups d'experts (per exemple, Rocard et al. 2007, Osborne i Dillon 2008) també se'n fan ressò. L'“èxit actual" (Léna 2009a) de tal mètode sembla invitar a difondre'l.

Els comentaris que recomanen aquest enfocament diuen esperar-ne una gran varietat de beneficis, que van des de la implicació dels alumnes en les ciències fins al desenvolupament del seu sentit crític i de les seves responsabilitats com a ciutadans.

Pel que fa als beneficis d'aprenentatge no es suggereix en cap cas que hagin de ser menors que

1 Inquiry Based Science Education- IBSE 
amb un ensenyament més tradicional. Tal com s'afirma, per exemple, a l'informe de Rocard i al. (2007), sembla que nombrosos autors esperen alts nivells d'èxit educatiu d'aquest tipus d'enfocament.

Tenint en compte aquesta impressionant unanimitat, serà útil examinar acuradament aquestes afirmacions optimistes per tal de discutir la manera de maximitzar les possibilitats d'èxit d'aquest moviment.

\section{ALGUNS ADVERTIMENTS}

Tot i no tractar-se d'una idea nova, el mètode basat en la indagació -en termes generals- ha estat durant molt de temps blanc de múltiples advertències. Una figura (fig. 1) en un article elaborat per Euler $(2004,193)$ resumeix l'essència de la qüestió a través d'un bucle estructural: s'entén el que es veu, es veu el que s'entén. "En la creació de nou coneixement", afegeix Euler, "l'evidència experimental és només una peça del trencaclosques. Un pas en un procés més llarg i, molt probablement, no és ni tan sols el pas decisiu".

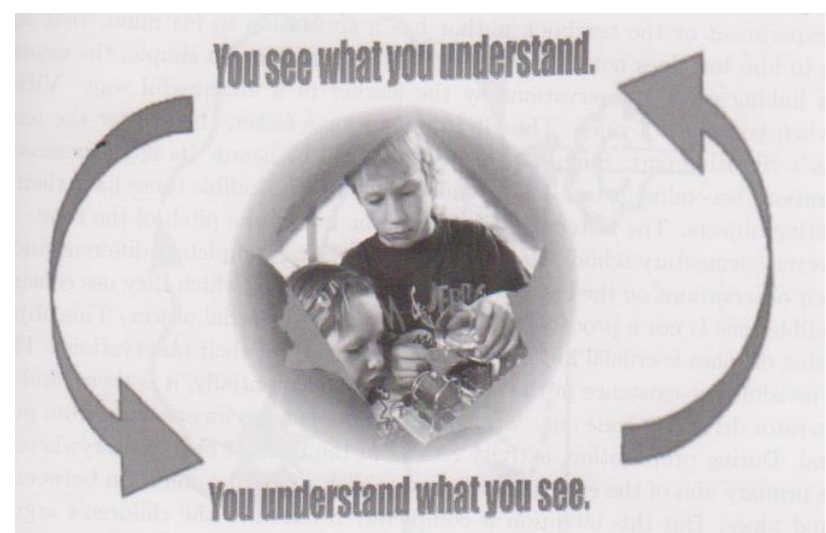

Figura 1. Figura extreta d'Euler (2004) i que il-Iustra la seva proposta de ser cauts a l'hora d'utilitzar l'experimentació en l'ensenyament

Alguns d'aquests advertiments, sostinguts des de fa temps, semblaven molt genèrics, però ressonen amb força en el context actual: "El model constructivista de l'aprenentatge no comporta necessàriament cap missatge sobre models d'ensenyament" (Millar 1989, 589). "Massa sovint, la qualitat de l'ensenyament es jutja sobre la base de l'entusiasme d'estudiants i mestres, $i$ això no és cap indicador vàlid" (McDermott, 1978).

Es feia èmfasi en el fet que qualsevol mètode d'ensenyament és ineficaç sense una consideració exhaustiva dels continguts a ensenyar (Lijnse 1994, 1995, 2002; Fensham i al. 1993), un punt de vista assumit pel que a Europa s'anomenà "la didàctica de", per exemple, "de la física".

En conseqüència, molts autors van destacar la necessitat que qualsevol seqüència d'ensenyament es dissenyi i s'avaluï a un nivell micro (Millar 1989; Lijnse ibid).

Finalment, els promotors de recents propostes per millorar l'ensenyament de les ciències "basantse en la indagació" eren conscients que hi havia hagut "al llarg dels anys 60 dels 70, (...), un nombre impressionant de reformes que havien fracassat" (Charpak 1996, en francès, p. 9).

Sembla que totes aquestes precaucions han tingut un ampli consens o com a mínim els actuals defensors de l'IBSE no les han negat explícitament. Com es pot conciliar aquesta realitat amb les grans proclames sobre els grans beneficis que s'esperen d'aquest enfocament de l'ensenyament de les ciències? En particular, podem pretendre tenir estudiants més "entusiasmats", més "apassionats per la física" i, al mateix temps, que entenguin de forma significativa el que volem que aprenguin? Podem fer alguna cosa millor que oferir als alumnes un conjunt dispers de classes estimulants? Podem guiar-los cap a una visió de la ciència concebuda com a descripció unificada del món material, construïda sobre la base de poques i predictives teories?

\section{AFRONTAR EL REPTE}

En aquest treball volem examinar la manera de conciliar l'entusiasme dels estudiants amb la seva pròpia estructuració conceptual. Aquest segon component, de fet, no és menys constitutiu de la ciència que l'anterior i fa referència a la pròpia naturalesa del tema: un conjunt de models i teories amb notable poder de predicció, consistència interna i l'elegant simplicitat, com va subratllar recentment Ogborn (1997, 2009).

Com podem sortir airosos d'aquest repte en el marc de l'IBSE? Un enfocament ja clàssic de l'IBSE és el següent. L'IBSE implica deixar molt de marge per la pròpia activitat intel-lectual dels estudiants.

Hi ha per tant una qüestió a resoldre, tenint en compte les expectatives prèvies dels alumnes. Quan la pregunta es refereix a un fenomen que pot il-lustrar-se pràcticament a petita escala, es dissenya i porta a terme un experiment.

Les expectatives sobre els resultats de l'experiment s'han de formular i justificar explícitament, per tal de generar i alimentar un debat entre els estudiants i/o entre els estudiants i el professor. Una vegada realitzat l'experiment, qualsevol divergència entre la predicció i el resultat obtingut ha de ser de- 
batuda. L'objectiu és que els alumnes assoleixin gradualment una visió compatible amb la física acceptada, o bé que formulin una nova pregunta.

Com s'ha dit en la introducció, aquests punts de vista són àmpliament compartits avui dia. En principi, són compatibles amb els diversos objectius assignats a aquest tipus d'ensenyament, en particular amb l'estructuració conceptual de l'alumne.

Podria ser, però, que l'ús predominant d'aquesta estratègia no potenciés especialment la comprensió organitzada dels conceptes ensenyats.

Es poden buscar maneres de superar algunes de les previsibles limitacions en aquest sentit. Per qüestió de brevetat, aquí encararem aquesta qüestió centrant-nos només en els alumnes i deixant de banda, per molt essencial que siguin, els professors $\mathrm{i}$ els formadors de docents (vegeu-ne alguns comentaris a l'Apèndix 1).

S'enumeren i analitzen a continuació alguns dels possibles obstacles perquè els alumnes assoleixin els objectius conceptuals, $i$ es proposen alguns exemples de pràctiques alternatives a les habituals, alternatives adreçades a reforçar els vincles conceptuals.

Els obstacles considerats a continuació es refereixen a tres idees principals: la complexitat dels fenòmens físics, algunes pràctiques rituals d'ensenyament $\mathrm{i}$ el que més avall es defineix com "explicació eco": un tipus de discurs utilitzat per professors o mediadors de ciència, especialment quan volen fer-se comprendre amb facilitat.

\section{LA COMPLEXITAT INTRÍNSECA DELS FENÒMENS FÍSICS}

Ens agradaria que la física fos una disciplina engrescadora i per tant intentem no espantar el públic amb explicacions massa complicades. Aquest fet comporta certes dificultats.

\section{Més enllà de buscar factors rellevants?}

Un enfocament molt raonable a la complexitat dels fenòmens, en un ensenyament basat en la indagació, és precisament ajudar als estudiants a aïllar les variables més rellevants, sempre que sigui possible. Aquesta és una font d'inspiració important per als dissenyadors de l'IBSE (veure, per exemple, l'emblemàtic tema del rellotge de sorra del projecte Pollen).

Per exemple, experimentar amb un pèndol $i$ constatar que la massa de l'objecte oscillant no afecta el període es pot considerar una activitat molt rica i engrescadora per als joves. No hi ha cap dubte que aquest tipus d'activitat, constitueix un primer pas per a una iniciació a la ciència i que el resultat no és en absolut obvi. De tota manera, donats els límits de les explicacions assequibles, no és tan fàcil garantir que es puguin transferir els coneixements que s'hi adquireixin.

Per exemple, com podem respondre la qüestió: Com és possible que la massa sigui irrellevant per al període de les oscillacions? Com podem justificar que, en el cas del sistema oscil-lant d'una massa a l'extrem d'una molla, la massa sí que sigui crítica?

Per tant, hem de ser conscients de la poca satisfacció que aquestes investigacions poden proporcionar a alguns alumnes. Per això, sigui quin sigui el públic amb qui es treballa és necessari trobar un equilibri entre la utilització d'experiments senzills i el desig dels alumnes d'obtenir explicacions satisfactòries.

\section{Quan el control de variables no ens diu totes les raons}

Dit això, no és qüestionable que el primer pas en un enfocament basat en la indagació ha d'incloure un acurat control de les variables.

En alguns casos l'experiment proposat està ben dissenyat i resulta indiscutible en aquest sentit, mostrant així que el seu dissenyador ha estat conscient de les possibles dificultats.

Aquest fou el cas de Marie Curie (1907: 27), o de documents oficials francesos per a alumnes de 10 anys (MEN 2008), o bé de Leach et al. (2010: 19) quan mostren com pesar aire en un recipient rígid, primer buidat i després omplert d'aire (fig. 2).

El volum constant de l'envàs garanteix que rebi una força ascensional d'Arquímedes constant. Llavors, l'elevat valor que es llegeix a la balança en el segon cas ha de ser atribuitt a l'augment de pes de l'envàs ja que aquest s'ha omplert d'aire.

Tot i així és manté una dificultat potencial. Encara que l'experiment no es pot rebatre, els estudiants i els professors podrien tornar a tenir problemes de generalització

Suposem que no s'expliqui per què es tria el contenidor rígid. Suggerir únicament que es tracta d'una qüestió de control de variables podria portarlos a un carreró sense sortida: per què mantenir constant el volum i no la pressió? Com podria comprendre un alumne que dues bosses similars plenes d'aire a la mateixa pressió atmosfèrica i a la mateixa temperatura, en aquesta ocasió una amb 
poc aire i l'altra amb molt més aire a l'interior, exerceixin exactament la mateixa força contra una balança?

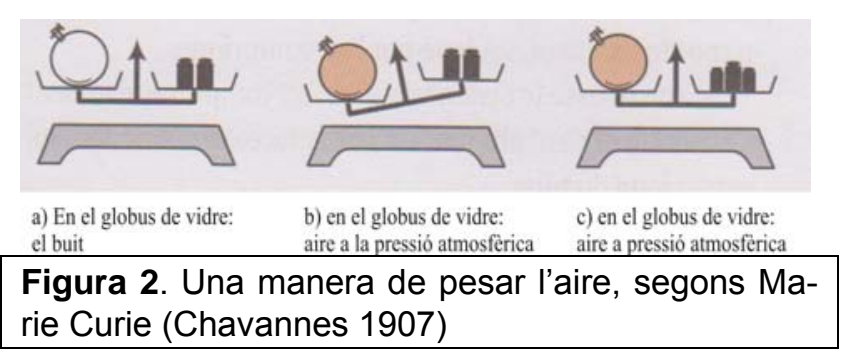

Fer èmfasi en els vincles conceptuals de la física significaria, en aquest exemple, aconseguir que els estudiants entenguin que la força exercida per un objecte sobre la balança no és necessàriament igual al seu pes (vegeu Annex 2).

També hauriem d'explicar per què triem el volum com la magnitud constant, i no la pressió ni la temperatura, abocant-nos inevitablement a parlar de la força ascensional d'Arquímedes. Llavors, la impressió de simplicitat podria desaparèixer.

Si pretenem que els alumnes s'engresquin amb la física i tractin d'ampliar la seva pràctica de recerca, llavors podria ser arriscat no revelar el que hi ha "darrere de la cortina" quan dissenyem un experiment inqüestionable.

Per tant, hem de considerar acuradament el balanç entre utilitat i riscos quan s'escull un experiment per a una sessió d'IBSE destinada a un determinat públic. Al contemplar l'explicació que s'hi vol donar s'ha de tenir ben en compte el possible preu a pagar per una simplificació aparentment "neutra"

Sigui quina sigui la decisió, hem de ser conscients dels seus límits i preparar-nos per respondre a les preguntes dels alumnes

\section{"Sí... però això és tan apassionant!"}

Volem que la física sigui atractiva per a molta gent i, per això, tendim a seleccionar fenòmens engrescadors mentre busquem explicar-los de la forma més senzilla possible.

En la discussió de l'explicació que es pot esperar que sorgeixi en una sessió d'IBSE, podem quedar impressionats per la capacitat de motivació d'un determinat context. Tot seguit veurem dos exemples amb els possibles riscos.

\section{Com volen els avions?}

Realment ens agradaria explicar de manera senzilla aquest meravellós fenomen. Gairebé inevitablement hem de recórrer a Bernoulli. El mateix passa quan es tracta de les boles "flotant" en un raig d'aire o diversos experiments anàlegs. Però el que queda del teorema en moltes explicacions és només que "com més velocitat, menys pressió, i com més pressió, menys velocitat" sense esmentar cap condició de validesa.

La principal dificultat és, doncs, la problemàtica generalització del que es diu. Per a moltes afirmacions simplificades hi ha contraexemples. Les mànigues de vent no són aspirades per una menor pressió en la seva part estreta, ja que de fet la velocitat és més gran allà que a l'entrada. Un fluid incompressible que flueix en una canonada horitzontal cilíndrica està a menor pressió a la seva sortida que a l'entrada, a causa de les forces de fricció, però la velocitat és semblant a tot arreu, etc.

Aquestes evidents contradiccions són conseqüències de la simplificació, que inclou obviar les condicions de validesa del teorema de Bernoulli. Per tant cal preguntar-se, en aquestes ocasions, si el preu a pagar val la pena.

Per descomptat, es pot reforçar l'explicació amb consideracions més precises. Però llavors és molt difícil evitar que la simplicitat s'esvaeixi.

El nostre segon exemple presenta un cas on és més fàcil sortir d'aquest dilema.

\section{Per tal d'introduir els fenòmens del color, podem tenir la temptació de triar un context familiar i utilitzar un aparell de televisió}

Es tracta d'un objecte quotidià on pots veure amb una lupa els punts vermells, blaus i verds de la pantalla. Si l'únic objectiu és que els alumnes s'adonin que si la pantalla es posa de color blanc això té alguna cosa a veure amb els colors vermell, blau i verd, l'experiment es pot conservar.

Però si tenim la intenció que els alumnes diferenciïn la mescla additiva de llum de la subtractiva de les mescles de pigments, l'opció pel televisor resulta problemàtica.

En efecte, no és en absolut evident de quina manera els punts de color -que estan visiblement separats a la pantalla- podrien tenir el mateix efecte que l'impacte simultani de feixos de llum en un punt concret d'una pantalla o de la retina. El mecanisme d'aquesta "barreja biològica", per dir-ho així, no és gens simple. 
És problemàtic comprendre com actuen les llums en aquesta història. Si l'objectiu conceptual és diferenciar els fenòmens de color, és aconsellable triar un altre experiment (per exemple Chauvet 1996, 1999: fig 3 i 4, vegeu també Viennot 2003; Planinsic 2004: Planinsic i Viennot 2010), tot i el context familiar que advocaria pel televisor.

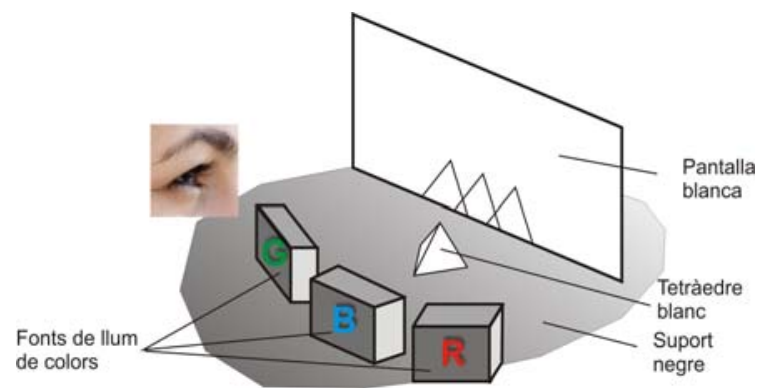

Figura 3. Croquis del muntatge utilitzat per realitzar l'experiment d'"ombres de colors" (Chauvet 1996, Chauvet 1999, versió lleugerament modificada: el tetràedre té una aresta paral·lela a la pantalla).

Amb aquests primers exemples ens enfrontem a algunes qüestions crucials, com ara: donat un fenomen per una sessió d'IBSE, els alumnes disposen de prou mitjans per interpretar coherentment el que observen? Quin tipus de conceptes els podem ajudar a construir?

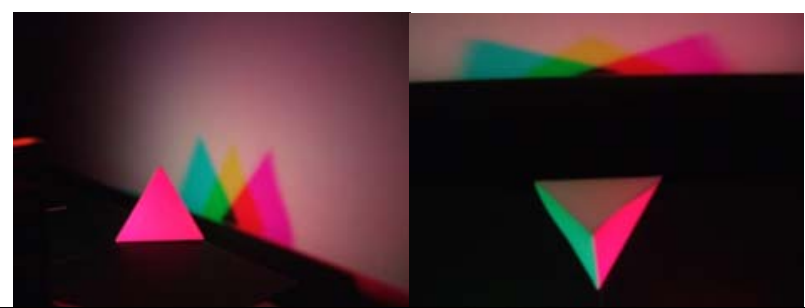

Figura 4: Els colors de les diferents zones del muntatge que es mostra a la figura 3 , una vegada encesos els llums. A l'esquerra, vista lateral, i a la dreta vista superior. (Fotos: P. Sauvage, ref. Planinsic i Viennot 2010).

Un tema atractiu serà suficient per garantir millors resultats d'aprenentatge? Tractar temes de la vida quotidiana és sempre la millor manera d'iniciar una sessió? És evident que s'ha d'escollir un fenomen que motivi al grup concret amb el que es treballa, tot tenint en compte quin tipus d'explicació és probable que sorgeixi durant la sessió IBSE. Però en aquest tipus de deliberació, les decisions poden resultar bloquejades, sobretot per algunes pràctiques rituals.

\section{MÉS ENLLÀ DELS RITUALS}

Hi ha moltes estratègies d'ensenyament, formes de presentar un experiment o unes explicacions que utilitzem repetidament com si no fossin problemàtiques. Aquestes pràctiques poden basar-se en l'experiència i en una reflexió acurada. No obstant, anomenarem "rituals" aquelles pràctiques que molt probablement són només resultat del costum.

Un exemple de ritual és l'experiència en la que un vas d'aigua invertit s'utilitza per demostrar el paper de la pressió atmosfèrica (Viennot 2009, Viennot 2010 a, b). Un vas ple d'aigua es cobreix amb un tros de cartolina i es posa de cap per avall, en posició vertical (fig. 5). L'aigua es queda en el vas, amb la cartolina aparentment enganxada a sota.

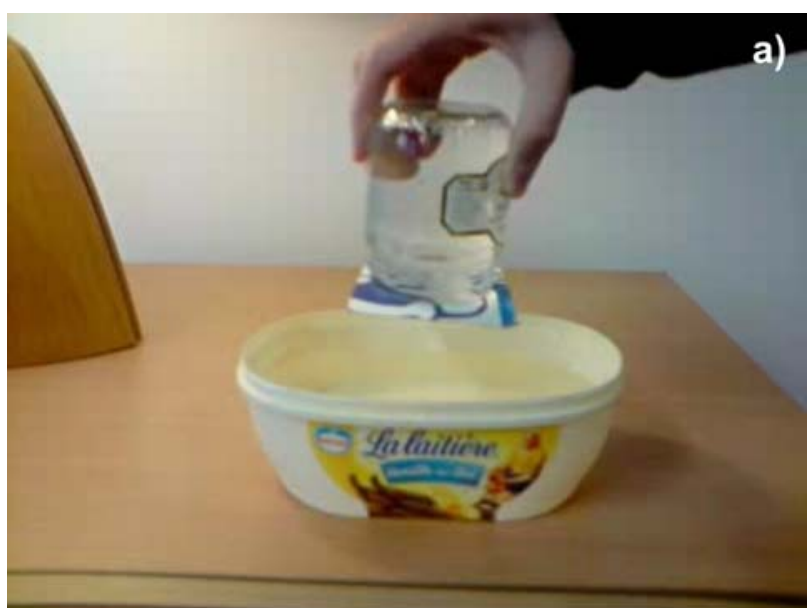

b)

Afirmacions que es troben sovint en explicacions comunes:

L 'aigua exerceix sobre el cartró una força igual al seu pes.

- La força deguda la pressió atmosfèrica que aguanta el cartró (per tant) fent que no caigui. c) Un diagrama que indica la desproporció (de fet sobre unes 100 vegades) entre els valors de les forces esmentades a (b):

- Cap amunt: força deguda a la atmosfèrica sobre el cartró.

- Cap avall: el pes de l'aigua pressió

Figura 5. Un experiment senzill (a) que sovint s'explica amb arguments problemàtics $(b, c)$.

S'explica sovint als alumnes que la cartolina no cau perquè l'atmosfera "aguanta el pes de l'aigua". $\mathrm{Hi}$ ha algun problema amb aquesta pràctica, en particular pel que fa a l'explicació? 
Aquesta explicació fa ús essencialment de dues forces, però suggereix un equilibri newtonià entre elles. De fet, la força cap amunt sobre la cartolina és aproximadament un centenar de vegades més gran que el pes de l'aigua. Per tant l'explicació anterior en el millor dels casos és molt incompleta, i en el pitjor dels casos, bastant incorrecta.

Una manera de mostrar que aquest exemple no és anecdòtic és considerar una segona situació: una mena de tub d'assaig ple d'aigua, collocat de cap per avall sobre un recipient amb aigua; la part superior del tub és $2 \mathrm{~m}$ damunt del nivell de la superfície lliure del recipient (fig. 6).

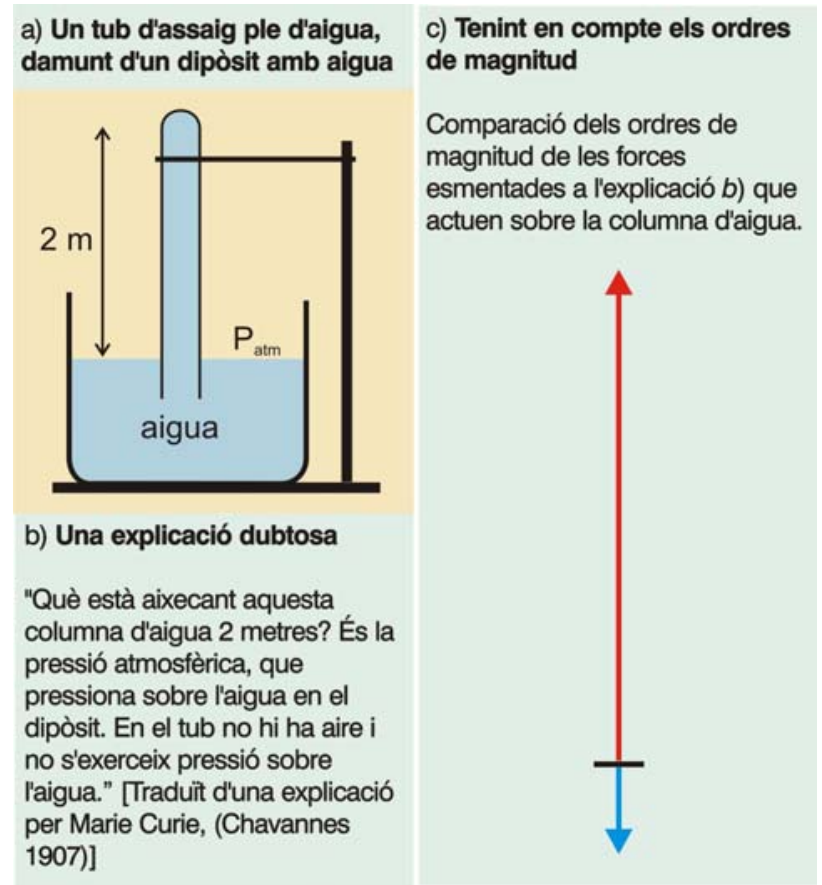

Figura 6. Una situació que pot ser analitzada com el got d'aigua de cap per avall (fig. 5): un tub d'assaig ple d'aigua i de cap per avall sobre un recipient amb aigua.

Aquesta situació és anàloga a la del vas d'aigua invertit. La pressió que rep l'aigua al nivell de la superfície lliure (és a dir, a la base de la columna d'aigua), com la que rebia la cartolina d'abans, és la pressió atmosfèrica. Igual que en el primer exemple, la interacció de contacte entre el vidre i l'aigua en la part superior del tub implica grans forces, que corresponen aquí a les quatre cinquenes parts de la pressió atmosfèrica (vegeu l'Apèndix 1).

Va ser Marie Curie qui va proporcionar una explicació experta d'aquest fenomen. Un llibre recentment publicat presenta les notes preses per Isabelle Chavannes durant les Iliçons donades el 1907 per Marie Curie a alguns dels fills dels seus amics (incloent-hi Isabelle). En relació al muntatge que es mostra a la fig. 6, Isabel Chavannes cita aquestes paraules de Marie Curie: "Què és el que està fent que s'aixequi aquesta columna d'aigua fins a $2 \mathrm{~m}$ ? És la pressió atmosfèrica la que està empenyent l'aigua del recipient. En el tub no hi ha aire i no s'exerceix pressió sobre l'aigua" (Chavannes 1907).

Amb aquest comentari és ja molt a prop de l'explicació comuna i problemàtica del vas invertit discutit més amunt. Aquesta similitud suggereix que el ritual que acabem d'il-lustrar amb el primer exemple -un vas invertit- no és simplement un accident. Per tant, creiem que val la pena suggerir alternatives, i no només assenyalar el caràcter incomplet de les explicacions rituals.

Una primera estratègia consisteix a canviar una mica la manera de presentar l'experiment del vas invertit i, posant-lo en una posició horitzontal (fig. 7). Llavors, és menys temptador atribuir la immobilitat de la cartolina a un equilibri entre la força exercida per l'atmosfera i el pes de l'aigua.

Una simple anàlisi de les components horitzontals de les principals forces condueix a una visió més simètrica, que és sistèmica i té en compte tots dos extrems del vas. L'atmosfera apareix jugant el paper d'una premsa més que la d'un suport. És probable que els resultats d'aprenentatge -0 al menys els obstacles conceptuals- siguin diferents.

El segon exemple no es presta a aquest tipus de canvi, ja que el tub d'assaig no es pot posar en posició horitzontal. Però segueix sent molt rellevant centrar-se en l'aspecte sistèmic. Igual que en el cas del vas invertit, ambdós extrems de la columna d'aigua mereixen atenció. De fet, a la part superior d'aquesta columna, la interacció entre l'aigua i el vidre és equivalent a la generada per quatre cinquenes parts de la pressió atmosfèrica.

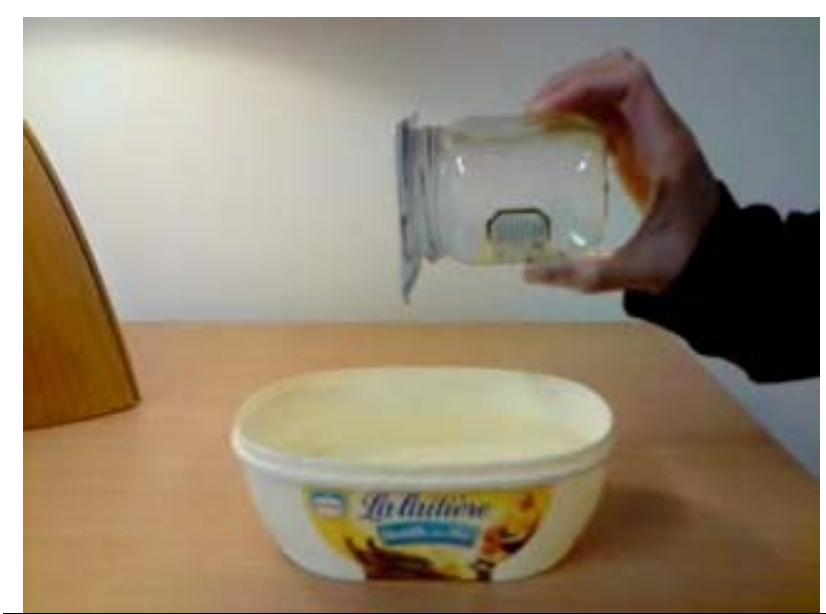

Figura 7. En posició horitzontal, l'aigua tampoc no surt del vas. 
Si subratllem els vincles entre les dues situacions - vidre invertit o tub d'assaig- és probable que ens ajudi a entendre millor d'aquesta idea. Fins i tot és possible discutir el que és un baròmetre de Torricelli, i subratllar que en aquest cas hi ha una interacció molt petita entre el vapor de mercuri i la part superior del tub $\left(\approx 2 \cdot 10^{-1} \mathrm{~Pa}\right)$. En fer èmfasi en les similituds i les diferències a través d'una anàlisi sistèmica, una investigació d'un got invertit, d'un tub d'assaig invertit i d'un baròmetre, donen accés a un contingut conceptual ric i coherent.

\section{EXPLICACIONS-ECO (QUE ES REPETEIXEN) PROCEDENTS DELS EXPERTS}

Els dos exemples anteriors il.lustren també la idea d'explicació-eco d'un expert (Viennot 2009, 2010, b, i Planinsic i Viennot 2009).

Anem a considerar les explicacions comunes $i$ problemàtiques que solen aparèixer en aquestes dues situacions. Es diu que una columna d'aigua s'aixeca per la pressió atmosfèrica i això suggereix un equilibri (desequilibrat) entre dues forces, ja que s'afirma (erròniament) o simplement s'insinua que no hi ha res més que actuï sobre l'aigua.

Aquestes dues forces són, d'una banda, la deguda a la pressió atmosfèrica a la base de la columna d'aigua i, d'altra banda, el pes d'aquesta columna que se suposa que s'exerceix sobre l'aigua en el recipient. Sembla que només es considera la base de la columna, com si no hi hagués cap interacció en la part superior.

Aquestes explicacions són compatibles amb algunes idees o formes de raonament molt comunes que repetidament observem en els alumnes.

De fet, sovint es pensa que un objecte "exerceix el seu pes sobre la base" (vegeu la discussió anterior sobre pesar l'aire) i que una anàlisi local és suficient. Llavors podem considerar que algunes explicacions d'experts es fan ressò de les concepcions comunes de molts alumnes, ja que semblen basar-se en les mateixes formes comunes de raonament.

En resum, a una "explicació eco" d'un expert se li poden atribuir les mateixes característiques de raonament que a les de molts alumnes i possiblement són errònies en relació a la física acceptada per la comunitat científica. Aquesta etiqueta d'explicació-eco no implica que existeixi cap relació de causalitat entre el que diuen els experts i els no especialistes, respectivament. Simplement assenyala una ressonància mútua.

\section{EXPLICACIONS ECO OUE RESSONEN AMB EL RAONAMENT LINEAL CAUSAL}

Molt sovint les explicacions eco es poden relacionar amb una forma molt comuna de pensar en la ciència: el raonament lineal causal.

Aquesta forma de raonament és de particular interès pel fet que és contrària a alguns models usats habitualment en la física acceptada, i en particular en la física elemental.

Considerem un sistema format per diversos objectes, per exemple dues molles, una a continuació de l'altra, penjades d'un suport i que un experimentador les estira (fig. 8), o bé un circuit en sèrie amb dues resistències $i$ una pila, o bé dos recipients cilíndrics plens de gas i separats per un pistó mòbil. Aquests sistemes es poden descriure utilitzant diverses variables relacionades de forma simple entre elles i lligades les unes a les altres. Per tant, la força que cada molla exerceix sobre l'altra és igual a la que aplica la mà de l'experimentador que tiba. Aquesta relació implica una situació d'equilibri mecànic en tots els punts alhora, i aquest mateix argument de temps es aplicable a cada valor específic de les magnituds en qüestió. En altres paraules: totes les parts del sistema combinat se suposa que "saben" de totes les altres parts de forma instantània, durant l'evolució -quasi-estàtica- d'aquest sistema.

Així, si l'experimentador tiba de l'extrem inferior, se suposa que la relació anterior d'igualtat de forces es manté en qualsevol instant, cosa gens evident. En el cas d'un terratrèmol, per exemple, aquest model no seria adequat per analitzar els canvis que afecten dues parts contigües d'un continent. Caldria canviar a un model de propagació.

L'evolució simultània de totes les parts d'un sistema està lluny de ser intuïtivament clara. Les formes més comunes per negar aquesta estranya hipòtesi prenen la forma del comentari típic següent (Fauconnet 1981: 111; Viennot 2001: 98) "La primera molla s'estirarà $i$, aleshores, al cap d'un temps la segona també s'estirarà". Aquest comentari suggereix que l'esdeveniment és vist com "una història", en comptes de canvis simultanis de diverses variables permanentment lligades per les mateixes relacions.

Els esdeveniments simples $\left(\varphi_{n}\right)$, molt sovint especificats a través d'una sola variable, es conceben com a sèries d'enllaços binaris de causa-efecte:

$$
\varphi_{1} \rightarrow \varphi_{2} \rightarrow \varphi_{3} \rightarrow(\ldots) \rightarrow \varphi_{n}
$$

(Rozier i Viennot 1991, Viennot 2001: capítol 5). 
Les fletxes utilitzades en l'expressió simbòlica anterior sovint s'expressen en paraules utilitzant l'adverbi "aleshores", un terme intermedi entre l'expressió d'un vincle lògic ("per tant") i un vincle temporal ("després").

Podem trobar el mateix tipus de terme ambigu en molts altres idiomes, per exemple "then" en anglès, "alors" en francès o "entonces" en espanyol. Més o menys subreptíciament, les explicacions comunes inclouen aspectes temporals.

La figura 8 compara terme a terme el raonament lineal comú $i$ una anàlisi quasi-estàtica, o quasiestacionària d'un canvi sistèmic.

\section{En la física quasi-estàtica}

Diverses variables

- Canvien al mateix temps

Limitades per relacions permanents

\section{Històries de causalitat lineal}

Fenòmens simples (una variable de cada un)

- Considerats successius (o com si ho fossin)

- Temporals

\section{Un exemple}

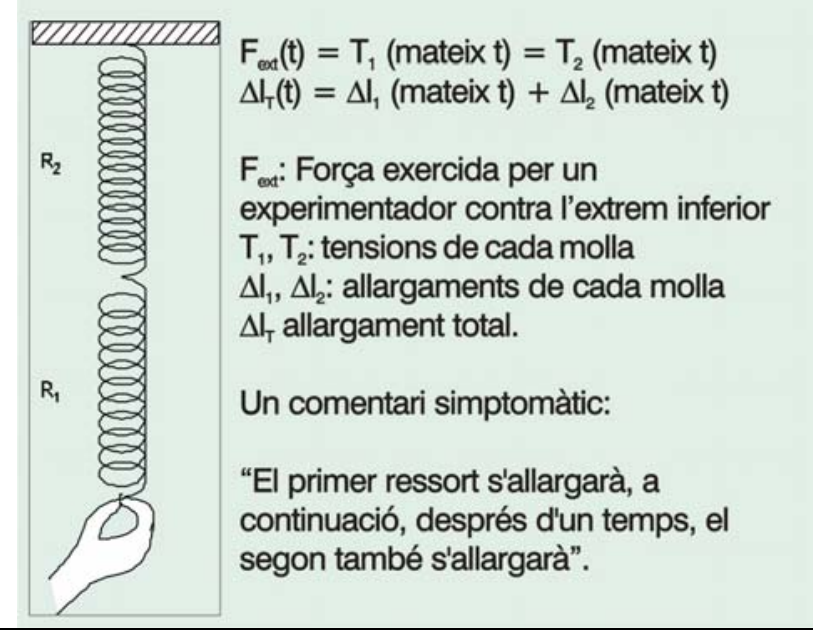

Figura 8. Les característiques principals del raonament causal lineal, en comparació amb les d'una anàlisi quasi-estàtica.

Com ja han assenyalat Rozier i Viennot (1991, vegeu també Viennot 2001: capítol 5), algunes explicacions d'experts també semblen ser fruit del raonament lineal causal, una forma de procedir particularment habitual per part d'autors de divulgació científica.
El següent exemple va ser assenyalat molt més recentment (Viennot 2010 a, b, Viennot i Planinsic 2009).

\section{Funcionament del sifó}

Una explicació, de nou aportada per Marie Curie (Chavannes 1907: 62), fa ús del següent argument: l'aigua surt de la branca llarga d'un sifó, es crea un buit, i la pressió atmosfèrica empeny l'aigua del dipòsit fins a la branca curta.

Utilitzant la presentació esquemàtica mostrada a la fig. 9, podríem parafrasejar aquesta explicació de la següent manera:

$\varphi_{1}$ (extrem esquerre del tub, a la figura 9): l'aigua surt de la branca llarga del sifó $\rightarrow \varphi_{2}$ (en algun lloc del tub) es crea un buit $\rightarrow \varphi_{3}$ (extrem dret del tub a la figura 9) la pressió atmosfèrica empeny amunt l'aigua del tanc per la branca petita.

Uns esdeveniments simples (per exemple, "el buit") es contemplen l'un darrera l'altra, com si es tractés d'una successió cronològica. Això sembla suggerir que és possible analitzar el que succeeix en un extrem del sistema, independentment del que succeeix en l'altre.

$\mathrm{Hi}$ ha un problema clar: el paper de l'atmosfera s'anomena a l'últim pas de l'explicació i es refereix a un sol extrem. Però també hi ha pressió atmosfèrica a l'altre extrem.

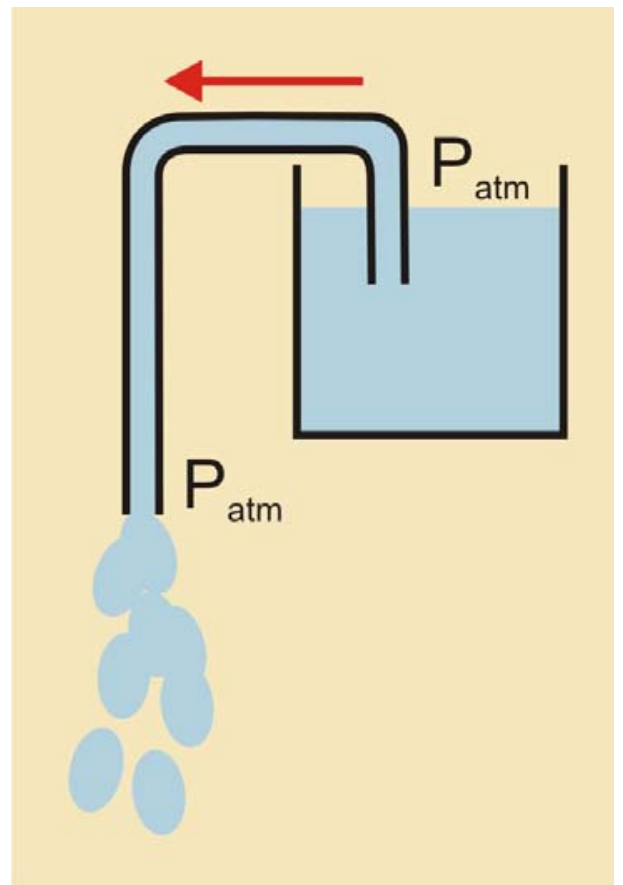

Figura 9. Sifó en funcionament. 
Els adjectius "llarg" i "curt" suposen una pista que discretament apunta cap al paper crucial d'una diferència. Molt probablement, aquesta pista no és suficient per als estudiants que encara no saben com analitzar aquest sistema. Podria pensar-se, per exemple, que l'aigua surt del "tub llarg", simplement perquè el seu extrem inferior està obert. La semblança entre aquesta explicació i el raonament lineal causal, clarament pot donar lloc a interpretacions inadequades.

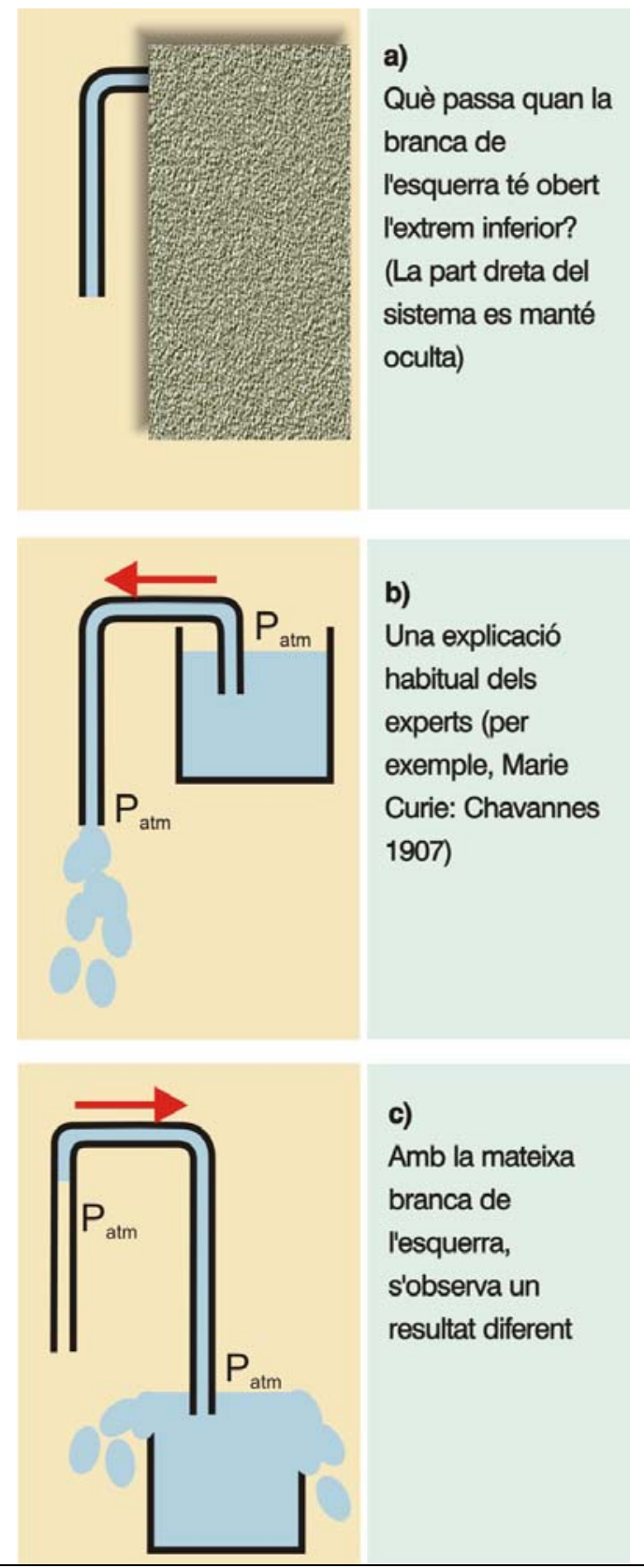

Figura 10. Sense tenir en compte ambdós costats d'un sifó, el resultat de l'experiment no es pot predir.

\section{FER ÈMFASI EN LES RELACIONS I EN EL PAPER DECISIU D'ALGUNES DIFERĖNCIES}

Els rituals i les explicacions-eco sovint coincideixen. Ser més conscients dels objectius d'ensenyament, analitzar-los críticament i especificar-los podria ampliar l'espai conceptual que pot resultar accessible als alumnes.

Per tant, encara que utilitzem el mateix dispositiu, es podrà decidir posar l'accent en l'aspecte sistèmic d'un sifó. Amb aquesta finalitat, es pot presentar als alumnes un sistema anàleg al que es mostra a la fig. 9, però ocultant la part dreta (fig. 10a) amb una pantalla; es podria demanar a l'alumne que predigui què passaria si el final curt de la branca esquerra, inicialment tapat, es destapés.

Un cop realitzat, l'experiment podria confirmar el que ordinàriament s'espera: l'aigua surt per la branca de l'esquerra. Quan es destapa (fig. 10b), els alumnes poden veure que es buida el vas, que és l'objectiu habitual de la utilització d'un sifó. Però l'experiment també podria realitzar-se amb un resultat diferent. Rere la pantalla, i amb exactament la mateixa part visible a l'esquerra, es pot posar el dipòsit d'aigua de forma que la superfície lliure estigui per sota del final de la branca esquerra (fig. 10c). Llavors, quan l'extrem esquerre del tub s'obre, l'aigua no surt i en canvi puja pel tub i torna a omplir el dipòsit.

Aquest és un sorprenent exemple que, sense veure ambdós extrems del sistema, és impossible predir el que l'aigua farà. Això és el més important que s'ha d'entendre sobre un sifó. Més enllà d'això, $a m b$ un muntatge modest, $\mathrm{i}$ amb una audiència que encara té un nivell de competència baix, és possible fer èmfasi en un aspecte fonamental dels fenòmens físics: el món funciona gràcies a les diferències (Boohan i Ogborn 1997).

Si tenim en compte aquest tipus de missatge en poques paraules: la importància d'un enfocament sistèmic- podem reorientar en conseqüència la posada en escena d'altres experiments, com ho demostra el següent exemple.

La figura 11 mostra un "mesurador d'amor". Quan s'escalfa la part inferior amb les mans es produeix un bonic efecte de font, fent que el líquid ompli parcialment la part superior, mentre el seu nivell disminueix en la part inferior.

L'explicació habitual és que l'escalfament del gas a la part inferior fa augmentar la pressió, i això fa empènyer el líquid cap amunt pel tub, unint-se la part inferior de baix amb la part inferior de dalt. Aquí hi trobem un altre raonament lineal causal. 
Per tal de ressaltar la idea clau més eficaçment, podríem formular l'explicació de manera més precisa, canviant "la pressió augmenta a la part inferior" per "la diferència de pressió entre les dues parts augmenta". Es tenen així en compte ambdues parts del sistema. Si tinguéssim present la importància de remarcar que són les diferències les que provoquen els canvis, seria natural completar la demostració clàssica de l'experiment del mesurador d'amor de la següent manera (fig. 12b): refredar la part superior, per exemple amb aigua freda. L'efecte és, per descomptat, el mateix que amb la versió normal, un efecte força sorprenent.

Entre altres activitats, aquests dos exemples sifó i mesurador d'amor- es podrien utilitzar per destacar la consistència de la física i la potència dels seus fonaments teòrics: en aquest cas la idea que el món funciona gràcies a les diferències.

\section{UN MÈTODE DE CONSENS, UNA VARIETAT DE RESULTATS POSSIBLES}

Els exemples anteriors, sobretot els dos últims, suggereixen una primera conclusió. Podríem estar

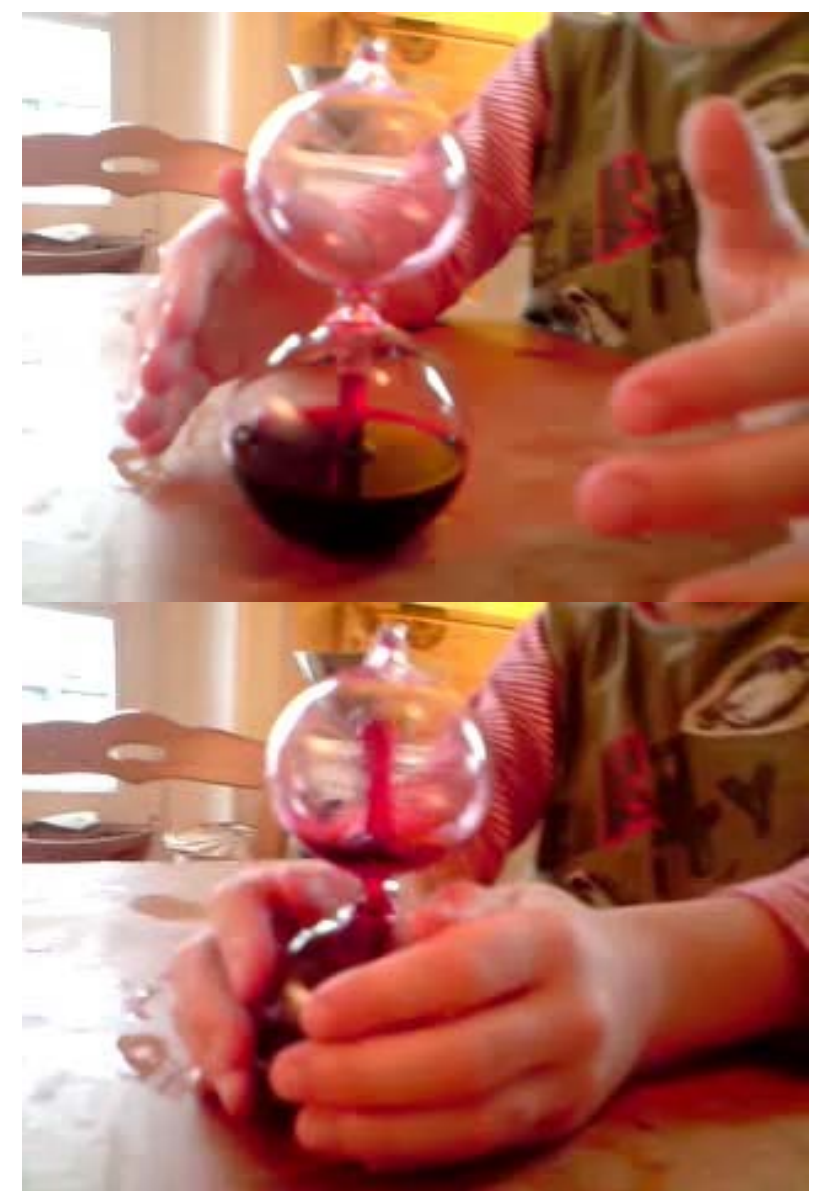

Figura 11. Un "mesurador d'amor" amb l'escenificació clàssica.

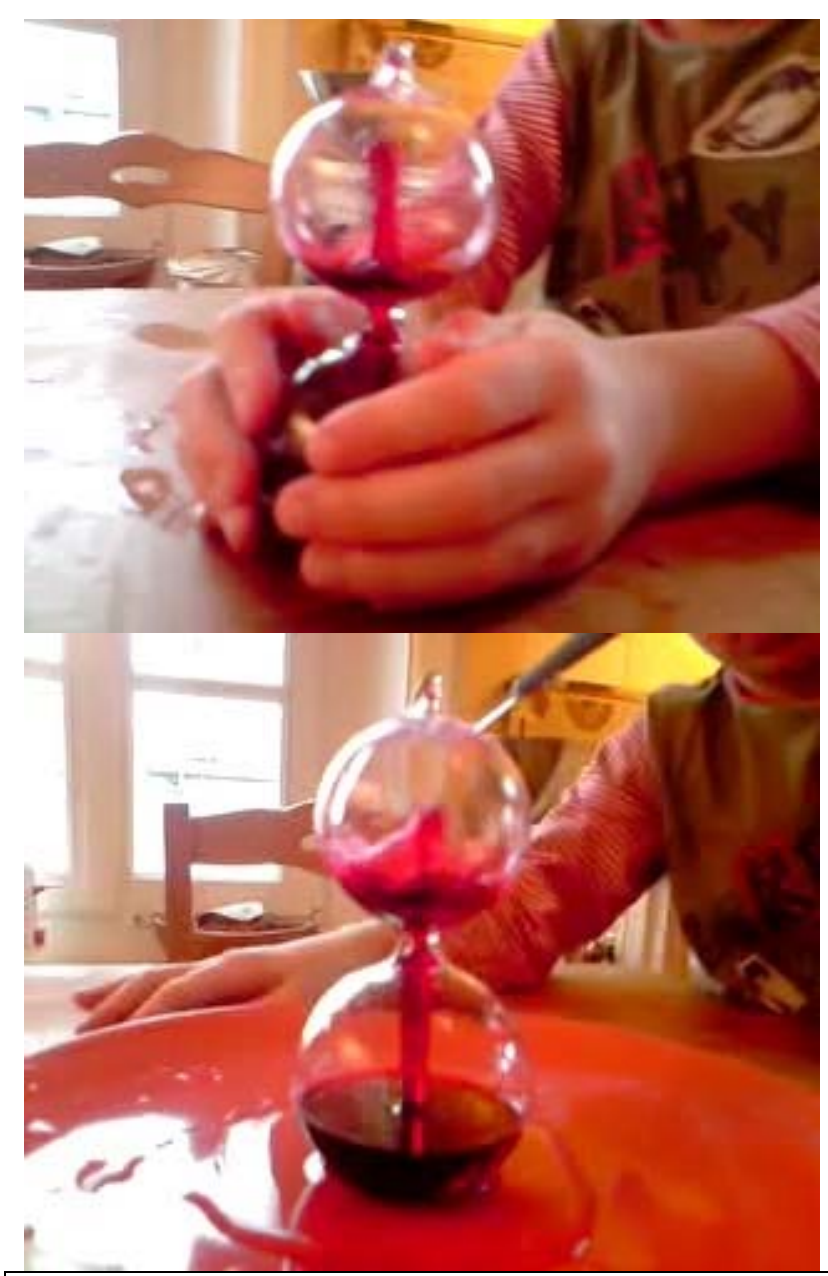

Figura 12. Una escenificació de l'experiment que condueix a una anàlisi sistèmica. A dalt, començant amb la utilització clàssica d'un "mesurador d'amor". A sota, refredant el recipient superior amb aigua freda.

d'acord sobre un marc pedagògic general que mantingui els alumnes actius, implicats, motivats, crítics, etc. Però dins d'aquest marc, el que queda per decidir és considerable, tal com ho és també el rang de possibles resultats.

El costat positiu d'aquest estat de coses és que hi ha marge de maniobra, sempre que es reconeguin i analitzin els límits d'algunes formes de procedir. Fins i tot quan hi ha importants obstacles per l'ensenyament, hi ha algunes opcions obertes i mecanismes per les accions que es volen portar a terme. Alguns canvis aparentment menors en les pràctiques rituals poden millorar molt els resultats.

Aquests "detalls crítics" de la pràctica (Viennot $i$ al. 2004), quan estan orientats per una sòlida anàlisi del contingut i per un coneixement suficient de les idees $\mathrm{i}$ formes comunes de raonament dels alumnes, possibiliten aconseguir una gran varietat d'objectius. 
Una condició prèvia és estar atents a les nostres pròpies explicacions, ja que poden reflectir alguns aspectes problemàtics del raonament comú. L'exploració de qualsevol contingut ve afectada pels objectius triats. Un d'aquests objectius podria ser remarcar els vincles conceptuals, destacant així el caràcter coherent, predictiu i concís que poden tenir les teories físiques en els seus àmbits de validesa.

\section{ALGUNES PREGUNTES CRUCIALS}

Com han recordat recentment molts textos a favor de IBSE “(...) el procés d'aprenentatge dels científics consisteix en: a) formular preguntes, fer experiments, recollir i comparar dades, arribar a conclusions i extrapolar aquests resultats a conclusions més generals". (Allende, 2008)

Per tant, una evocació constant sobre la ciència és la del seu enfocament interrogador. Per ser consistents no hauríem de començar amb aquesta actitud, en relació amb l'IBSE. En aquest article es recorda i es mostren alguns problemes, es suggereixen algunes raons $\mathrm{i}$ algunes maneres per ser prudents i alhora estar positivament compromesos amb I'IBSE. És evident que amb això estem lluny d'esgotar el tema. Entre les preguntes crucials que resten obertes, ens trobem amb:

\section{Com podem avaluar les nostres afirmacions sobre I'IBSE?}

Com hem recordat en la introducció, s'han fet moltes afirmacions per justificar i acompanyar el procés de reactivació dels enfocaments IBSE. Tenint en compte els fracassos anteriors dels anys 70 , hi havia una necessitat urgent d'avaluar formalment els resultats, després d'una dècada de "recent" IBSE.

Com que aquest treball se centra en els alumnes, s'ha de tenir en compte que en aquest sentit els resultats disponibles, més enllà dels informes fets pel professorat, van ser molt escassos fins fa poc.

S'ha realitzat recentment una avaluació formal a gran escala en el marc del projecte Pollen (20062009). Una de les qüestions examinades era si I'IBSE realment fomentava el gust dels alumnes per la ciència. Uns resultats sorprenents es refereixen a una promoció d'alumnes, amb edats entre 10 i 11 anys, que van seguir durant dos anys, a Berlín, a I'IBSE, administrant-los pre-test i post-test.

La majoria de les puntuacions individuals relatives al gust dels alumnes pels experiments científics també baixa significativament al llarg dels dos anys (...), en els que les puntuacions de les nenes baixen encara més. Aquest patró en què disminueix el gust per la ciència a l'escola a mida que els alumnes de primària creixen (Jarvis i Pell, 2002, Piburn \& Baker, 1993) és comú en molts països. No ha de sorprendre que no hi hagi un canvi notable en les respostes típiques dels alumnes pel fet de seguir el Projecte Pollen."

Aquest comentari contrasta vivament amb moltes proclames. Demostra la utilitat d'una actitud lúcida i no dogmàtica.

En primer lloc, sembla que hem de buscar les variables rellevants pertinents, que aquesta vegada es refereixen a I'IBSE, per tal de comprendre millor els seus resultats. En aquest sentit, la investigació realitzada per Jarvis i els seus companys proporciona resultats interessants.

Els alumnes de Leicester $(\mathrm{N}=301-554$, amb edats entre 7 i 11 anys), se'ls va demanar que puntuessin diversos ítems amb una escala Likert de cinc nivells. Es va trobar que l'item "la ciència és massa difícil", va rebre una puntuació significativament més baixa després d'un any de l'IBSE.

En canvi, no es van observar diferències significatives respecte dels ítems "(...) esbrinar per què l'experiment funciona" i "la ciència em fa pensar". Sorprenentment, s'obtenen els mateixos tipus de resultats en la investigació duta a terme en diversos països europeus per Lindahl (2009), també dins del projecte Pollen.

Aquests estudis ens poden ajudar a millorar la nostra pràctica. Aquí, en particular, els resultats plantegen la qüestió de desenvolupar un component més conceptual de I'IBSE. En efecte, la ciència no presenta dificultats insuperables, al menys a partir d'algunes respostes d'alumnes, però tampoc sembla intel-lectualment estimulant després d'un llarg període d'ensenyament basat en la indagació.

\section{Com afecta I'IBSE als resultats conceptuals dels alumnes i a la seva satisfacció intel-lectual?}

La recerca en Didàctica de la física s'ha dedicat a l'avaluació de la comprensió dels conceptes científics dels alumnes abans, durant i després de l'ensenyament.

En canvi, la recent reactivació de l'IBSE va estar sovint acompanyada d'avaluacions gairebé exclusivament centrades en les actituds dels alumnes o dels professors envers la ciència (vegeu, per exemple, la investigació de Pollen, que acabem d'esmentar). Com s'ha recordat anteriorment, és necessari continuar avaluant "a un nivell micro" el que 
els alumnes realment comprenen dels conceptes científics, en diferents condicions d'ensenyament.

A més de la qüestió dels resultats conceptuals dels alumnes i, probablement molt lligat a aquest aspecte, el nivell de satisfacció intel-lectual dels alumnes és un punt crucial a investigar.

La satisfacció intel-lectual rau en la confluència entre l'afectivitat i el progrés conceptual. És un sentiment Iligat a la impressió d'haver entès fins a cert punt un tema complex, que es pot identificar amb força claredat, i que s'aconsegueix amb una bona relació qualitat / costos (Viennot 2006, Mathé i Viennot 2009, Feller $i$ al. 2010).

Sovint, els factors afectius es contemplen com a condicions rellevants per a l'aprenentatge (per exemple, Pintrich $i$ al. 1993; Rhöneck $i$ al. 1998; Glynn $i$ al. 2007, Launkenmann i al. 2003). Però la satisfacció intel-lectual, vista com un possible resultat de l'aprenentatge, està -probablement- íntimament relacionada amb un dels principals objectius dels projectes IBSE: mantenir els alumnes compromesos amb la ciència a llarg termini.

\section{IBSE des de l'escola primària fins al final de l'escola secundària: quines transicions?}

Aquest punt ens porta a un aspecte crucial de I'IBSE: la transició d'un ensenyament principalment enfocat a la indagació científica, cap a un enfocament més sistemàtic per una organització conceptual de la ciència. Com van recordar Rocard i al. (2007: 12), "els dos enfocaments no són mútuament excloents, $i$ poden $i$ han de combinar-se en qualsevol classe de ciències per adaptar-se a diferents tipus de temes, a diferents mentalitats $i$ a diferents preferències segons quin sigui el grup d'edat."

A la pràctica, la combinació entre ambdós que s'ha d'adoptar en un context determinat no és en absolut evident. Podem trobar diversos suggeriments sobre els passos crucials a seguir. Així, d'acord amb Lena (2009b), hi hauria, en alguns països europeus, una edat d'or "dels 5 als 16" per portar a terme enfocaments basats en la indagació: "En els quatre països (França, Alemanya, Països Baixos $i$ Suècia), l'ensenyament de les 'ciències com a indagació' promou que els alumnes (de 5 a 16 anys) desenvolupin un sentit per preguntar-se, per observar i per raonar de manera lògica.

Osborne i Dillon, recomanem que aquest enfocament sigui el prevalent "abans dels 14 anys": "Els països de la UE haurien de vetllar perquè: (...) l'èmfasi en l'educació científica abans dels 14 involucri els estudiants amb la ciència $i$ els fenòmens científics.
L'evidència suggereix que això s'aconsegueix millor a través de donar oportunitats per la realització de treballs de recerca amplis i d'experimentació pràctica que no pas a través d'insistir en l'adquisició dels conceptes canònics" (Osborne i Dillon, 2008: 9) .

És summament important que es faci una profunda reflexió sobre com i quan gestionar les transicions decisives. Per solucionar aquest problema, cal dur a terme urgentment programes d'investigació acuradament dissenyats.

\section{OBSERVACIONS FINALS}

Aquestes qüestions crucials - unes poques d'entre moltes altres- poden semblar desencoratjadorament complexes. Recullen només alguns dels debats recurrents en l'ensenyament de les ciències $i$ no hi ha raó perquè l'IBSE els hagi d'esquivar.

El veritable repte és mantenir el magnífic impuls donat recentment a I'IBSE, tot tenint en compte aquestes preguntes i mantenint un esforç lúcid per al progrés en aquests aspectes.

Podem dir, si més no, que una condició per a l'èxit és rebutjar qualsevol maniqueisme. Phil Scott fa ben poc expressava la seva preocupació sobre aquesta tendència: "Una tendència preocupant que detecto és la de que es donen nous enfocaments situant-los en oposició entre si en una dicotomia poc saludable (...) D'altra banda, i amb massa freqüència, els enfocaments per a l'ensenyament de coneixement científic conceptual són qualificats de 'tradicionals', 'didàctics' i 'dolents', mentre que els enfocaments entorn a la indagació es veuen com a 'innovadors', 'centrats en l'alumne" $i$ 'bons'." (Scott 2009).

Encara que l'esmentat informe Rocard deia clarament que "els dos enfocaments no són mútuament excloents...", en la pràctica, una o dues frases útils en un informe no són suficients per garantir un enfocament d'ensenyament de tot el temari que sigui generalitzat, harmoniós i eficaç. Per a aquesta finalitat, seria molt fructífer, suggereixo, considerar seriosament la idea que és essencial que els alumnes assoleixin un cert grau de satisfacció intel.lectual.

En aquest sentit, un important mecanisme -també per la perspectiva d'ensenyament basat en la indagació- és afavorir l'estructuració conceptual, remarcant els vincles entre els fenòmens i les lleis. Així, les diferents raons perquè la ciència agradi podrien reconciliar-se en una sinergia eficient. Podríem esperar tenir alumnes que realment i a llarg termini s'impliquessin en la ciència, més enllà d'un entusiasme passatger. 


\section{REFERÈNCIES}

Alberts, B. 2008. Considering Science Education, Science, 319, 21-3-2008. Editorial. p. 1589

Allende, J.E. 2008. Academies Active in Education, Science, 321, 29-8-2008. Editorial.

Boohan, R. \& Ogborn, J. 1997. Differences, energy and change: a simple approach through pictures, New ways of teaching physics-Proceedings of the GIREP International Conference 1996 in Ljubliana, S. Oblack, M.Hribar, K. Luchner, M. Munih, Board of Education Slovenia.

Charpak, G. 1996. La main à la pâte. Les sciences à l'école primaire. Flammarion, p. 9.

Charpak, G. 2005. La main à la pâte. Science et Avenir. n. 698, Avril 2005. p. 11

Chauvet, F. 1996. Teaching colour: designing and evaluation of a sequence, European Journal of Teacher Education, vol 19, n², pp 119-134.

Chauvet, F.1999. STTIS Project, Colour sequence University "Denis Diderot", LDAR (Laboratoire de didactique André Revuz); and STTIS (Science Teacher Training in an Information Society) web sites: (retrieved 1.7.2010):

http://www.lar.univ-paris-diderot.fr/sttis_p7/color_sequence/page_mere.htm or: http://crecim.uab.cat/websttis/index.html

Chavannes, I. 1907. Physique élémentaire pour les enfants de nos amis. Leçons de Marie Curie, recueillies par Isabelle Chavannes en 1907. Dir. B. Leclercq, Paris: EDP Sciences, 2003

Euler, M. 2004. The role of experiments in the teaching and learning of physics. Research in physics Education, Varenna course CLVI, Amsterdam: IOS Press, pp. 175-221.

Fauconnet, S. 1981. Etude de résolution de problèmes: quelques problèmes de même structure en physique, Thèse de troisième cycle, Université Paris 7.

Feller, I., Colin, P. \& Viennot, L. 2009. Critical analysis of popularisation documents in the physics classroom. An action-research in grade 10. Problems of education in the 21st century. 17 (17): pp.72-96.

Fensham. P,. Gunstone, R \& White, R. (Eds) 1994. "The Content of Science: a constructivist approach to its teaching and learning", The Falmer Press, London

Glynn, S. M., Taasoobshirazi, G., \& Brickman, P. 2007. Nonscience majors learning science: $A$ theoretical model of motivation. Journal of Research in Science Teaching, 44 (8), PP.10881107.

Jarvis, T. \& Pell, A. 2002. Changes in primary boys' and girls' attitudes to school and science during a two-year science in-service programme. The
Curriculum Journal 13 (1), pp. 43-69.

Jarvis, T., Pell, A. \& Hingley, P. 2009. Pollen Primary Teachers'Changing Confidence and Attitudes over Two Years Pollen In-service:

www.pollen-europa.net/

Laukenmann, M., Bleicher M., Fub, S., Glâser-Zikuda, M., Mayring, P., \& Rhöneck, C. V. 2003. An investigation of the influence of emotional factors on learning in physics instruction. IJSE, 25 (4), pp.489-507.

Leach, J. \& Scott, P. 2002. Designing and evaluating science teaching sequences: an approach drawing upon the concept of learning demand and a social constructivist perspective on learning. Studies in Science Education, 38, pp. 115142.

Leach, J. \& Scott, P. 2003. Learning science in the classroom: Drawing on individual and social perspectives. Science and Education, 12 (1), pp. 91-113.

Leach, J., Ametller, J. \& Scott, P. 2010. Establishing and communicating knowledge about teaching and learning scientific content: The role of design briefs, In K. Kortland (ed.): Designing Theory-Based Teaching-Learning Sequences for Science Education. Utrecht: $\mathrm{Cd} \beta$ press, pp. 9-38.

Léna, P. 2009a. Towards an European strategy in elementary science education. In G. Santoro (ed.), "New Trends in Science and Technology Education" Conference, Abstract booklet, Università di Modena e Reggio Emilia, p. 71.

Léna, P. 2009b. Europe rethinks education, Science, 326, 23-11-2009

Lijnse, P.L. 1994. La recherche - développement: une voie vers une "structure didactique" de la physique empiriquement fondée, Didaskalia n.3, pp. 93-108.

Lijnse, P.L. 1995. 'Developmental research' as a way to an empirically based 'didactical structure' of science. Science Education, 79, 189-199.

Lijnse, P.L. 1998. Curriculum development in physics education. In E. Sassi and M. Vicentini (Eds.): Physics Education: recent developments in the interaction between research and teaching, International Commission of Physics Education:

web.phys.ksu.edu/icpe/Publications/index.html

Lijnse, P.L. 2002. Didactics of science: the forgotten dimension in science education research. In R. Millar, J. Leach and J. Osborne (Eds.): Improving Science Education - The contribution of research, Buckingham: Open University Press. pp. 308-326.

Lindahl, B. 2009. Changes in pupils' attitudes towards science during two years within the Pollen 
project: www.pollen.europa.net

Mathé, S., \& Viennot, L. 2009. Stressing the coherence of physics: Students journalists' and science mediators' reactions, Problems of education in the 21st century. 11 (11), pp. 104-128.

McDermott L.C. 1998. Research in Physics Education, International Newsletter on Physics Education (ICPE-IUPAP), 36, 1-3. (p. 3)

Millar, R. 1989. Constructive criticisms, International Journal of Science Education, Special issue, 11 (5), pp. 587-596.

MUSE http:/leducation.epsdivisions.org/muse/

Nillsen, R. 2009. Can the love of learning be taught? The Pantaneto forum, 36 : www.pantaneto.co.uk/issue 36/nillsen.htm

Ogborn, J. 1997. Constructivist metaphors of learning science. Science \& Education, 6, pp. 121133.

Ogborn, J. 2009. Science and common sense. In E. Sassi and M. Vicentini (eds.): Physics Education: recent developments in the interaction between research and teaching, (section A1), International Commission of Physics Education: http://web.phys.ksu.edu/icpe/Publications/index. $\mathrm{html}$

Ogborn, J. 2010. Curriculum development as practical activity. In K. Kortland (ed.): Designing Theory-Based Teaching-Learning Sequences for Science Education. Utrecht: Cdß press, 71-80.

Osborne, J.. Dillon, J. 2008. Science Education in Europe: Critical Reflexions. Nuffield Foundation: www.nuffieldfoundation.org/fileLibrary/pdf/Sci_E d in Europe Report Final.pdf

Piburn, , M.D. \& Beker,D.R. 1993. If we were the teacher ...Qualitative Study of Attitude towards Science. Science Education, 77, 393-406.

Pinto, R. (coord.), Ogborn, J., Quale, A., Sassi, E. \& Viennot, L. 2001. STTIS:"Science Teacher Training in an Information Society"), European Commission, Brussels N. SOE2-CT97 20 20: http://crecim.uab.cat/websttis/index.html

Pintrich, P. R., Marx, R. W., \& Boyle, R. A. 1993. Beyond cold conceptual change: The role of motivational beliefs and classroom contextual factors in the process of conceptual change. Review of Educational Research, 63 (2), 167-199.

Planinsic, G. \& Viennot, L. 2010. Stories of light, Muse project, URL:

http://education.epsdivisions.org/muse/

Planinsic, G. 2004. Color Light mixer for every student, The Physics Teacher, 42, pp. 138-142

Posner, C. J., Strike, K. A., Hewson, P. W. \& Gertzog, W. A. 1982. Accommodation of a scientific conception: toward a theory of conceptual change. Science Education 66 (2), pp. 211-227.

Rhöneck, C. V., Grob, K., Schnaitmann, G. W., \&
Völker, B. (1998). Learning in basic electricity: how do motivation, cognitive and classroom climate factors influence achievement in physics? International Journal of Science Education, 20 (5), pp. 551-565.

Rocard, Y. 2007, Science Education Now, Report EU22-845, European Commission, Brussels: http://ec.europa.eu/research/sciencesociety/document_library/pdf_06/report-rocardon-science-education_en.pdf

Rozier S., Viennot L. 1991, Students' reasoning in thermodynamics, International Journal of Science Education, Vol $13 \mathrm{n}^{\circ} 2$, pp. 159-170.

Scott, P. 2009. Teaching Physics Concepts: A neglected Art? Plenary address, GIREP 2009 Leicester.

STTIS: http://www.lar.univ-parisdiderot.fr/materiaux-pedagogique/sequencemodule

Viennot, L. 2001. Reasoning in physics. The part of common sense, Brussels: Kluwer.

Viennot L. 2003. Teaching physics. With the collaboration of U. Besson, F. Chauvet, P. Colin, C. Hirn-Chaine, W. Kaminski, S. Rainson. Trad. M. Greenwood \& A. Moisy. Dordrecht: Kluwer Ac. Pub.

Viennot, L., Chauvet, F., Colin, P. \& Rebmann, G. 2004. Designing Strategies and Tools for Teacher Training, the Role of Critical Details. Examples in Optics. Science Education, 89 (1), pp. 13-27.

Viennot, L. 2006. Teaching rituals and students' intellectual satisfaction. Physics Education, 41, 400-408.

Viennot, L. 2009. Some experiments in fluids statics, In Planinsic, G., Sassi, E., Ucke, C. and Viennot, L., MUSE project, URL: http://education.epsdivisions.org/muse/

Viennot, L. \& Planinsic, G. 2009. The siphon: a staging focused on a systemic analysis, MUSE project of the EPS-PED:

http://education.epsdivisions.org/muse

Viennot, L. 2010a. Physics by inquiry: beyond rituals and echo-explanations, In L. Menabue \& G. Santoro (Eds.) New Trends in Science and Technology Education: Selected papers, CLUEB, Bologna

Viennot, L. 2010b. Physics education research and inquiry-based teaching: a question of didactical consistency, In K. Kortland (ed.): Designing Theory-Based Teaching-Learning Sequences for Science Education. Utrecht: Cd $\beta$ press, 3956.

Weltin, H. 1961. A paradox. American Journal of Physics, 29 (10), pp. 712-711. 


\section{APÈNDIX 1}

\section{Com ajudar i formar professors perquè duguin a terme I'IBSE acuradament?}

Tenint en compte les limitacions d'espai no hem discutit alguns temes importants en relació amb el professorat en el text anterior. Però, com s'ha dit en diverses ocasions, el paper dels docents és absolutament decisiu.

Com sempre quan es proposa una innovació en un sistema educatiu, o fins i tot s'experimenta a petita escala, els mestres són transformadors actius del disseny proposat (per exemple, STTIS 2000, Leach $i$ al. 2002, Millar 2010, Ogborn 2010).

No hi ha dubte que, per tal d'ajudar els professors a donar el primer pas, és molt útil donar-los consideracions generals sobre l'IBSE, juntament amb exemples, com els publicats en una web de recursos (LaMap, Pollen, Sinus Transfer), o fins i tot kits. Les sessions presencials de formació o les sessions de classe acompanyades, sempre que siguin possible, són, per descomptat, per afavorir una millor interacció entre els dissenyadors i els professors que se suposa que s'han apropiar de la innovació recomanada.

En qualsevol cas, seria molt discutible adoptar un enfocament de transmissió: l'etiqueta "l'exemplaritat" és molt qüestionable, perquè el que és aconsellable en un context d'ensenyament determinat (professor inclòs), pot ser molt problemàtic en un altre.

Per exemple, com van assenyalar Jarvit i al. (2009): "Els kits són una estratègia valuosa per donar suport a les escoles $i$ als professors amb poca experiència en ensenyament de les ciències. (...) A llarg termini, els kits poden inhibir la creativitat $i$ l'entusiasme dels docents."

En conseqüència, pot ser útil per a qualsevol tema de la física proposar un menú, ja sigui amb recursos de la xarxa o sense. Això podria incloure, a més d'alguna informació sobre el contingut, una descripció de les idees habituals dels alumnes, una anàlisi crítica de les possibles pràctiques rituals explicacions o formes de presentar un experimenti suggeriments d'alternatives juntament amb les seves justificacions, construïdes en conseqüència.

Tenint en compte que els professors tracen la seva pròpia ruta quan decideixen què fer l'endemà, aquest format hauria d'incitar-los a prendre la responsabilitat de la consistència didàctica de la seva elecció personal; és a dir, es tractaria de buscar que els objectius de l'ensenyament fossin coherents amb les estratègies escollides, donades les idees dels alumnes prèvies a la instrucció i les reaccions que se'n poden esperar.

Més àmpliament, aquesta idea d'una consistència didàctica podria constituir el concepte clau de les sessions de formació del professorat. Després, en línia amb l'enfocament de plantejament de problemes (Lijnse 1995, 1998, 2002), els professors podrien formar-se per avaluar en quina mesura algunes propostes escolars (Leach et al. 2010) són didàcticament consistents. Diverses pàgines web de recursos (STTIS, MUSE) es basen en aquests principis.

\section{APÈNDIX 2}

\section{Una anàlisi elemental de la situació del "vas invertit", amb diagrames desplaçats}

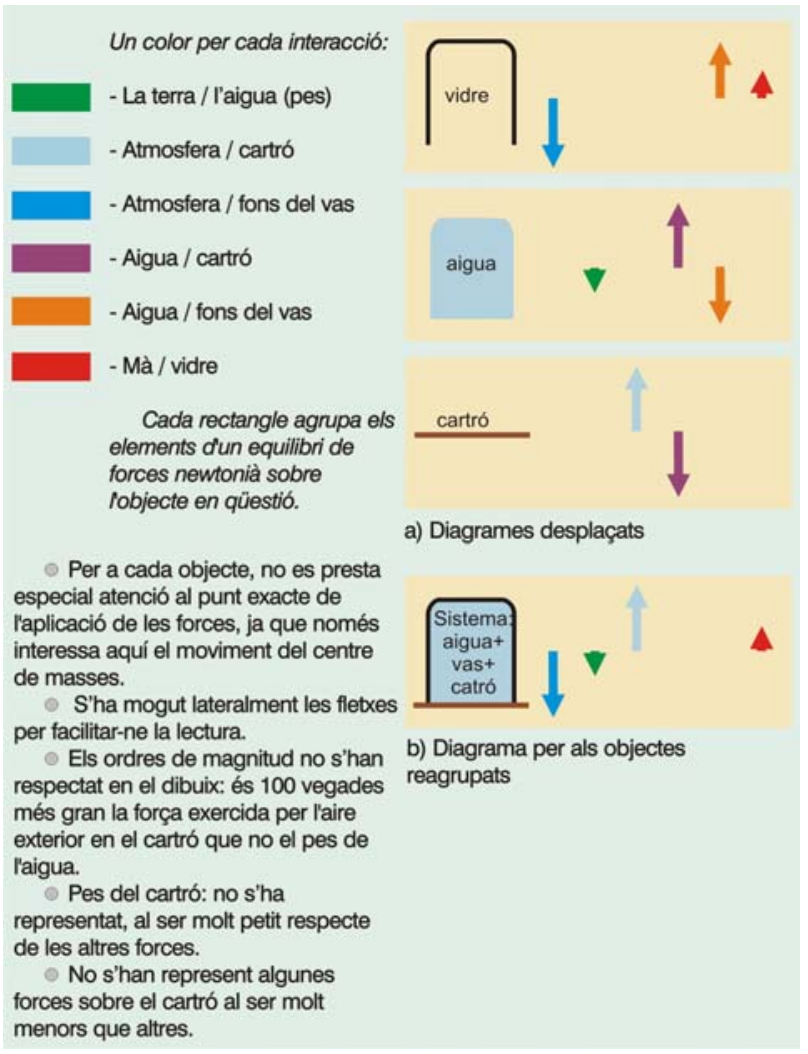

Les forces principals (components verticals) en la situació del vas ple d'aigua invertit (per més detalls, mireu Weltin 1961, Viennot $i$ al. 2009): (a) mostra una vista detallada del sistema aiguavidre-cartró on les fletxes indiquen les forces d'interacció, (b) mostra l'equilibri entre les diferents forces que actuen sobre el sistema d'aigua + vas + cartró. 